\title{
The potential impact of a deep geologic repository for used nuclear fuel on non-human biota
}

\author{
N.C. Garisto, F. Cooper and S.L. Fernandes \\ SENES Consultants Limited, 121 Granton Drive, Unit 12, Richmond Hill, \\ L4B 3N4 Ontario, Canada
}

\begin{abstract}
This study presents and implements a screening methodology for assessing the potential postclosure radiological impact of a deep geological repository (DGR) for used nuclear fuel on non-human biota. This screening methodology is designed for hypothetical sites representative of selected Canadian conditions under both present and potential future climate conditions. The screening is carried out by comparing estimated radionuclide concentrations to derived "No Effect Concentrations" (NECs). The NECs are screening or threshold criteria; the conservative nature of the assumptions used to derive the NECs ensures that as long as the NECs are not exceeded, there is confidence that, despite uncertainty in modelled environmental concentrations, there will be no significant ecological effect on non-human biota. In the event NECs are exceeded in screening calculations, a site-specific Ecological Risk Assessment would be required to determine whether this is due to conservatism in the assumptions, lack of sufficient data or potential real impact. The NECs derived in this study were compared to other threshold criteria from U.S. and international literature.
\end{abstract}

\section{INTRODUCTION}

The objective of this paper is to develop and implement a screening methodology for assessing the potential post-closure radiological impact of a deep geological repository for used nuclear fuel on non-human biota. Chemical toxicity impacts are not addressed in this study. The paper addresses the question: would a deep geological repository for used nuclear fuel have a significant radiological impact on non-human biota in Canada? The screening methodology is designed for hypothetical sites representative of selected Canadian conditions under both present and potential future climate conditions.

\section{METHODOLOGY}

The methodology for assessing the potential impact of a repository of used nuclear fuel on non-human biota involves the estimation of reference "No Effect Concentrations", or NECs for radionuclides in environmental media to which non-human biota are exposed [1]. The screening is carried out by comparing estimated radionuclide concentrations to these NECs. The NECs are screening or threshold criteria; the conservative nature of the assumptions used to derive the NECs ensures that as long as the NECs are not exceeded, there is confidence that, despite uncertainty in (measured or modelled) environmental concentrations, there will be no significant ecological effect on non-human biota. In the event are exceeded, a site-specific Ecological Risk Assessment (ERA) would be required to determine whether this is due to conservatism in the assumptions, lack of sufficient data or potential real impact.

NECs are developed in this study for three ecosystems that represent a broad range of Canadian conditions now and in the future (e.g. glaciation): southern Canadian deciduous forest, boreal (Canadian Shield) forest, and inland tundra. Several indicator species are evaluated for each ecosystem, representing a range of different trophic levels within the ecosystem. For example:

- Southern Canadian deciduous forest - Representative specific indicator species such as benthic lake fish (e.g. white sucker), pelagic lake fish (e.g. round whitefish), muskrat, deer and wild turkey. 
- Boreal (Canadian Shield) forest - Representative specific indicator species such as beaver, ruffed grouse, moose, wolf and common loon.

- Inland tundra - Representative specific indicator species such as lichen, arctic char, caribou, arctic hare, arctic fox and ptarmigan.

The selection of radionuclides for this study was based primarily on the results of previous conceptual case studies: the Third Case Study (TCS) - Defective Container Scenario and the Horizontal Borehole Concept (HBC) - Defective Container Scenario [2,3]. These scenarios assume that some containers are emplaced in the repository with small undetected defects. This allows groundwater to enter the container and contact the fuel, thereby providing a pathway for release of radionuclides into the groundwater surrounding the repository. Other post-closure assessments considered in this paper include the Environmental Impact Statement (EIS) [4] and the Second Case Study (SCS) [5].

NECs were developed for a set of 12 reference radionuclides: C-14, Cl-36, Zr-93, Nb-94, Tc-99, I-129, Cs-135, Ra-226, Np-237, U-238, Pb-210 and Po-210.

This list of radionuclides includes the main contributors to human dose from the Third Case Study and its extension to a Horizontal Borehole Emplacement concept. In addition, representative activation radionuclides are included. This list of radionuclides is also similar to that identified in other international assessments, such as Nagra [6], ANDRA [7] and SKB [8,9].

\subsection{Derivation of NECs}

The overall approach taken for calculating NEC values for each radionuclide in a given environmental medium in each ecosystem is described below and illustrated in Figures 1 and 2. The following steps are involved:

- Select the ecological receptor categories and individual indicator species to be included in the derivation of NECs.

- Define the ecological profile for each indicator species. The profile includes the amount of water, food and soil/sediment consumed, as well as a determination of the food types that comprise the diet.

- Collect information needed to model environmental behaviour and transfer for each radionuclide. NECs are calculated for water, sediment, soil and groundwater concentrations. To determine the concentration in different biota (e.g. fish, terrestrial plants), it is necessary to be able to estimate the concentration in all environmental media through the use of transfer factors. Transfer factors estimate radionuclide concentrations in the whole body of the specified biota with uniform distribution. For more complex biota, radionuclide concentrations in the body were calculated via multiple intake pathways. Transfer factors were, in general, selected from readily available information.

- Compile Dose Coefficients (DCs) for each radionuclide for both internal and external exposure, from readily-available information/compilations.

- Select appropriate dose rate criteria (ENEVs) for the various indicator species, from readilyavailable information/compilations.

- Calculate the dose for unit concentrations of radionuclides in water. For each radionuclide, calculate the dose that biota would receive from a concentration of $1 \mathrm{~Bq} / \mathrm{L}$ in water, assuming sediment, soil and groundwater concentrations are zero. This procedure is carried out for each radionuclide for each biota that is exposed to water. This unit dose calculation step is then repeated for all other media: soil (i.e., by setting concentrations of each radionuclide in soil equal to one and all other concentrations equal to zero), sediment and groundwater.

- For each of the radionuclides in each of the base environmental media (i.e. water, sediment, soil, groundwater), back-calculate the concentration of radionuclide that corresponds to the selected $E N E V$. For example, calculate the concentration of $\mathrm{C}-14$ in water that would generate a dose to common loon of $1 \mathrm{mGy} /$ day (the selected ENEV for loon). Repeat for each medium and each relevant biota.

- Group the biota by ecosystem: Southern Canadian Deciduous Forest, Boreal Forest or Inland Tundra. 
- Select the lowest back-calculated concentration value for each radionuclide. These concentrations, termed No Effect Concentrations (NECs), are generic and can be applied at a variety of sites within each ecosystem.

Graphical representations of the exposure pathways and food chains for aquatic and terrestrial biota were produced. Figure 1 shows an example, relevant for the terrestrial biota in the Boreal Forest ecosystem.

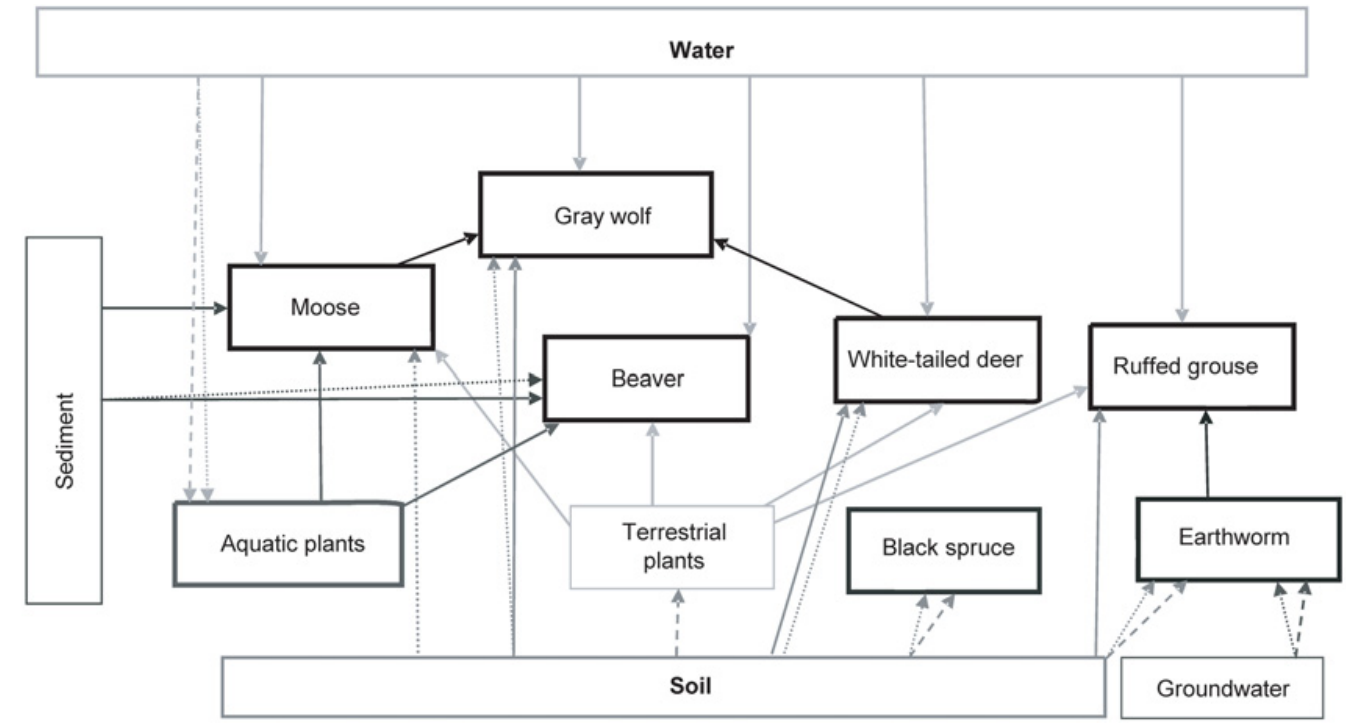

Figure 1. Exposure pathways and food chain for the terrestrial biota in the boreal forest ecosystem. Indicator species are shown in bold boxes. Dashed lines indicate that exposure and concentration are modelled through the use of transfer factors (TFs). The TF is assumed to account for direct and indirect pathways. Solid lines indicate that exposure is modelled by estimating the intake. Dotted lines indicate an external exposure pathway.

\subsection{Application of NECs}

As discussed above, the NEC corresponding to the most limiting biota for each radionuclide in a particular environmental medium is used as a concentration screening level for a particular ecosystem. A sum-of-fractions rule has to be used to ensure that total dose over radionuclides and/or over pathways in a given ecosystem does not exceed the estimated no-effect dose-rate values (i.e., radioecological dose benchmarks for population-level effects on biota; these values are compiled from literature). The overall approach for application of NECs is shown in Figure 2.

\section{RESULTS AND CONCLUSIONS}

NECs were derived for each radionuclide in each medium (see Table 1 for representative results) and were compared to estimated post-closure environmental concentrations. Detailed results are provided in Garisto et al. [10].

\subsection{NEC derivation}

Two sets of NEC values were derived, using different parameters in the calculations. These correspond to an Upper Estimate case and a Central Estimate case. The Upper Estimate values are more conservative than the Central Estimate values. The degree of conservatism in each of these sets of parameters is 


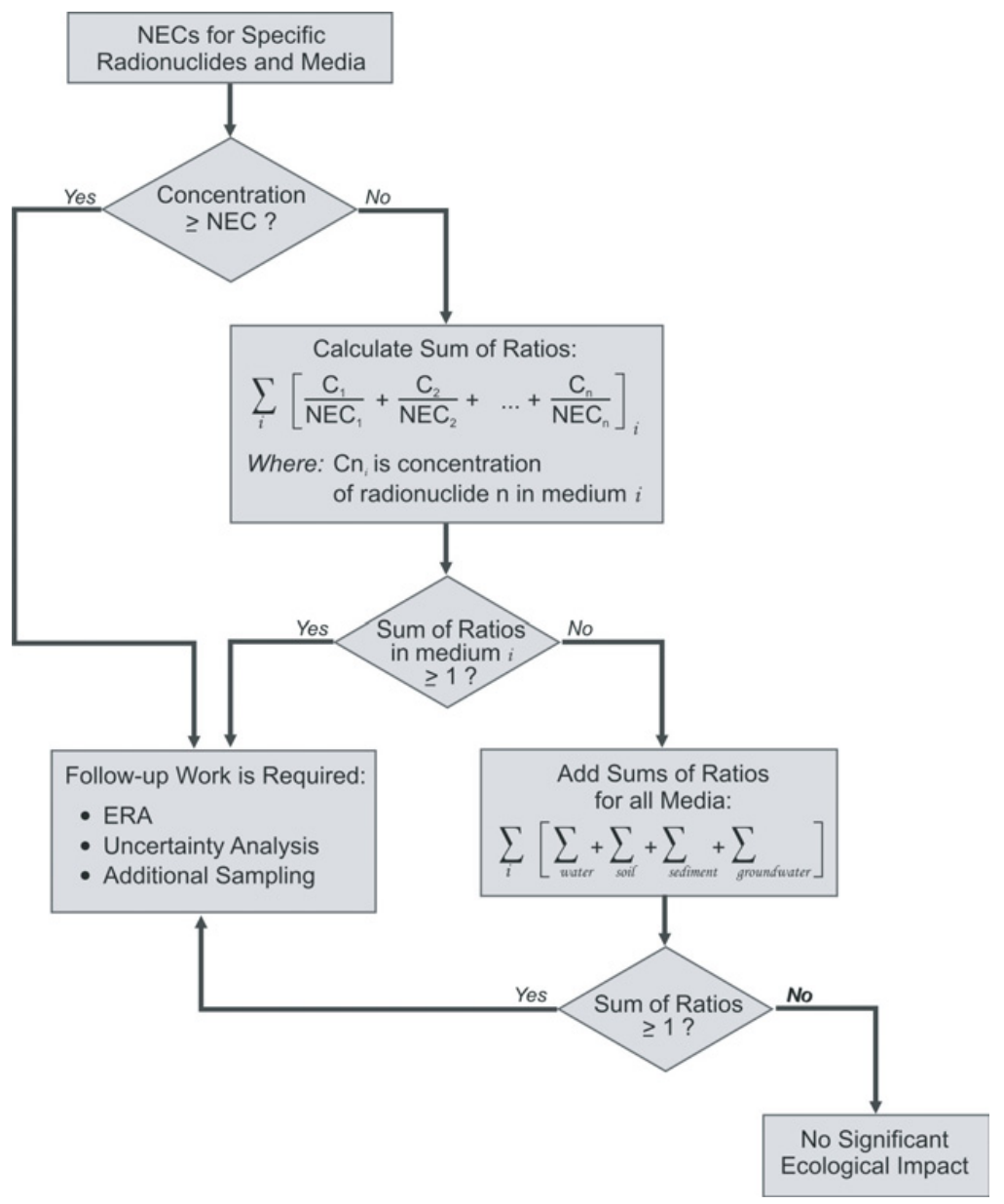

Figure 2. Schematic flowchart of NEC application.

discussed below. The same dietary intake rate and exposure data were applied to the Central and Upper Estimate calculations. The results presented below are for the Upper Estimate case.

Table 1 shows the NEC values that were derived for radionuclides in water, for the different ecosystems. The NECs derived for other media are presented in Garisto et al. [10].

Table 2 shows the radionuclide with the lowest NEC in each medium and each ecosystem, for both the Central and Upper Estimates.

Table 3 shows the biota with the lowest NEC for each radionuclide and each medium. Results are shown for the Boreal Forest ecosystem.

\subsection{Impact assessment}

Table 4 shows the sums-of-ratios calculated for each medium. The ratios were calculated by comparing the maximum estimated post-closure environmental concentrations to the NECs. The NECs used in calculating the sums of ratios are the lowest (i.e., the most restrictive) concentrations across the three ecosystems studied. 
Table 1. Estimated no-effect concentrations (NECs) calculated for radionuclides in water (Bq/L).

\begin{tabular}{|c|c|c|c|c|}
\hline \multirow{2}{*}{ Radionuclide } & \multicolumn{4}{|c|}{ Ecosystem } \\
\cline { 2 - 5 } & S.Cdn. Deciduous & Boreal Forest & Inland Tundra & All Ecosystems \\
\hline C-14 & $2.40 \mathrm{E}-01$ & $2.69 \mathrm{E}-02$ & $7.01 \mathrm{E}-01$ & $2.69 \mathrm{E}-02$ \\
\hline Cl-36 & $3.11 \mathrm{E}+00$ & $2.78 \mathrm{E}+00$ & $6.30 \mathrm{E}+00$ & $2.78 \mathrm{E}+00$ \\
\hline Zr-93 & $1.75 \mathrm{E}+00$ & $1.75 \mathrm{E}+00$ & $2.94 \mathrm{E}+02$ & $1.75 \mathrm{E}+00$ \\
\hline Nb-94 & $1.57 \mathrm{E}-02$ & $4.54 \mathrm{E}-03$ & $8.30 \mathrm{E}-01$ & $4.54 \mathrm{E}-03$ \\
\hline Tc-99 & $7.95 \mathrm{E}-01$ & $7.95 \mathrm{E}-01$ & $5.71 \mathrm{E}+02$ & $7.95 \mathrm{E}-01$ \\
\hline I-129 & $3.23 \mathrm{E}+00$ & $3.23 \mathrm{E}+00$ & $1.57 \mathrm{E}+02$ & $3.23 \mathrm{E}+00$ \\
\hline Cs-135 & $2.54 \mathrm{E}-01$ & $2.13 \mathrm{E}-03$ & $9.71 \mathrm{E}-01$ & $2.13 \mathrm{E}-03$ \\
\hline Ra-226 & $5.86 \mathrm{E}-04$ & $5.86 \mathrm{E}-04$ & $1.78 \mathrm{E}-01$ & $5.86 \mathrm{E}-04$ \\
\hline Np-237 & $5.77 \mathrm{E}-02$ & $5.77 \mathrm{E}-02$ & $5.84 \mathrm{E}-02$ & $5.77 \mathrm{E}-02$ \\
\hline U-238 & $2.30 \mathrm{E}-02$ & $2.30 \mathrm{E}-02$ & $4.19 \mathrm{E}-01$ & $2.30 \mathrm{E}-02$ \\
\hline Pb-210 & $4.95 \mathrm{E}+00$ & $4.27 \mathrm{E}+00$ & $4.01 \mathrm{E}+01$ & $4.27 \mathrm{E}+00$ \\
\hline Po-210 & $7.04 \mathrm{E}-03$ & $7.04 \mathrm{E}-03$ & $2.01 \mathrm{E}-02$ & $7.04 \mathrm{E}-03$ \\
\hline
\end{tabular}

Table 2. Radionuclide with lowest NEC in each medium and each ecosystem.

\begin{tabular}{|c|c|c|c|c|}
\hline \multirow{2}{*}{ Medium } & \multicolumn{4}{|c|}{ Ecosystem } \\
\cline { 2 - 5 } & S. Cdn. Deciduous & Boreal Forest & Inland Tundra & All Ecosystems \\
\hline Water & Ra-226 & Ra-226 & Po-210 & Ra-226 \\
\hline Soil & Cl-36 & Cl-36 & Cl-36 & Cl-36 \\
\hline Sediment & Ra-226 & Ra-226 & Ra-226 & Ra-226 \\
\hline Groundwater & Po-210 & Po-210 & not calculated & Po-210 \\
\hline
\end{tabular}

Table 3. Limiting biota for each radionuclide and medium in boreal forest ecosystem.

\begin{tabular}{|c|c|c|c|c|}
\hline \multirow{2}{*}{ Radionuclide } & \multicolumn{4}{|c|}{ Medium } \\
\cline { 2 - 5 } & Water & Soil & Sediment & Groundwater \\
\hline C-14 & Loon & Wolf & Muskrat & Worm \\
\hline Cl-36 & Wolf & Wolf & Muskrat & Worm \\
\hline Zr-93 & Muskrat & Wolf & Benthic Fish & Worm \\
\hline Nb-94 & Wolf & Wolf & Wolf & Worm \\
\hline Tc-99 & Muskrat & Wolf & Muskrat & Worm \\
\hline I-129 & Muskrat & Wolf & Muskrat & Worm \\
\hline Cs-135 & Loon & Grouse & Loon & Worm \\
\hline Ra-226 & Muskrat & Grouse & Benthos & Worm \\
\hline Np-237 & Muskrat & Beaver & Benthos & Worm \\
\hline U-238 & Muskrat & Grouse & Loon & Worm \\
\hline Pb-210 & Loon & Grouse & Benthos & Worm \\
\hline Po-210 & Muskrat & Beaver & Beaver & Worm \\
\hline
\end{tabular}

The methodology discussed above suggests that once the sum of ratios has been calculated for each medium, the total sum of ratios in all media be calculated. This is a conservative approach. The overall sums-of-ratios are also shown in Table 3.

As seen in Table 4 below, all of the overall sums-of-ratios are below one. This result indicates that there is no potentially significant radioecological impact from the disposal of used nuclear fuel on nonhuman biota. This result was obtained for ecosystems representing current Canadian climate conditions (e.g., southern Canadian deciduous forest, boreal Canadian Shield forest) as well as potential far-future climate conditions such as a tundra ecosystem.

\subsection{Discussion}

The general approach taken of comparing conservative NECs to measured/modelled media concentrations and expressing the as a ratio (summed for multiple radionuclides) is compatible with 
Table 4. Overall sum of ratios from post-closure safety assessment studies.

\begin{tabular}{|c|c|c|c|c|}
\hline & \multicolumn{4}{|c|}{ Post-Closure Safety Assessment Study } \\
\hline Medium & EIS & SCS & TCS & HBC \\
\hline Water & n/a & n/a & $1.03 \mathrm{E}-04$ & $9.88 \mathrm{E}-05$ \\
\hline Soil & $5.90 \mathrm{E}-05$ & $3.23 \mathrm{E}-06$ & $1.57 \mathrm{E}-04$ & $3.59 \mathrm{E}-05$ \\
\hline Sediment & $7.42 \mathrm{E}-08$ & $2.71 \mathrm{E}-07$ & $2.13 \mathrm{E}-08$ & $1.81 \mathrm{E}-08$ \\
\hline Groundwater & $2.28 \mathrm{E}-06$ & $4.15 \mathrm{E}-07$ & $2.22 \mathrm{E}-06$ & $2.34 \mathrm{E}-06$ \\
\hline Total & $\mathbf{6 . 1 4 E - 0 5}$ & $\mathbf{3 . 9 1 E - 0 6}$ & $\mathbf{2 . 6 2 E - 0 4}$ & $\mathbf{1 . 3 7 E - 0 4}$ \\
\hline
\end{tabular}

that taken by the U.S. DOE (RESRAD-BIOTA) [11] and the European-funded ERICA Integrated Approach [12]. This Appendix provides a comparison to the Biota Concentration Guide (BCG) values derived by the U.S. DOE [11] and the Environmental Media Concentration Limits (EMCLs) presented in ERICA [12].

The comparison showed that while these approaches are similar in concept, the results are not the same:

- Most of the BCGs are not within the range of Central and Upper estimate NEC values. All of the BCGs that are outside the range of NECs are greater than the NEC values.

- Many of the EMCL values are similar to (or between) the Central and Upper Estimate NECs. Those that are not between the NEC values are typically less than the NECs.

This is due to numerous factors, such as different modelling parameters and different definitions of effects. For example, in the derivation of ERICA EMCLs, the incremental screening dose rate was set to $10 \mu \mathrm{Gy} / \mathrm{h}$ for all ecosystems; however, the ERICA Tool [12] does allow for user-inputted variation in this value. The effect benchmarks (ENEVs) selected for the present study are specific to biota groups and are from a variety of sources/effects. For example, the UNSCEAR/IAEA values are applicable to the most exposed individuals within a population, whereas the Garnier-Laplace values are EDR ED $_{10}$ (dose rate giving $10 \%$ change in observed effect) and HDR5 (hazardous dose rate giving $10 \%$ effect to $5 \%$ of species) values.

\section{Acknowledgments}

This study was partially funded by the Canadian Nuclear Waste Management Organization. Constructive technical comments received from T. Kempe, F. Garisto, P. Lum, P. Gierszewski, N. Beresford and B. Howard are gratefully acknowledged.

\section{References}

[1] Garisto, N.C., S.L. Fernandes, M. Monabbati, D. Brown, and F. Bajurny. 2005. Screening "NoEffect Concentrations" for Radionuclides in the Abiotic Environment from a Generic Ecological Risk Perspective: Derivation and Application to the Pickering Nuclear Site. Proceedings of the 2nd International Conference on Radioactivity in the Environment, 2-6 October 2005 in Nice, France.

[2] Garisto, F., J. Avis, N. Calder, A. D’Andrea, P. Gierszewski, C. Kitson, T.W. Melnyk, K. Wei and L. Wojciechowski. 2004. Third Case Study - Defective Container Scenario. Ontario Power Generation Report No. 06819-REP-01200-10126-R00. Toronto, Canada.

[3] Garisto, F., J. Avis, N. Calder, P. Gierszewski, C. Kitson, T.W. Melnyk, K. Wei and L. Wojciechowski. 2005. Horizontal Borehole Concept Case Study. Ontario Power Generation Report No. 06819-REP-01200-10139-R00. Toronto, Canada.

[4] Atomic Energy of Canada Limited (AECL) 1994. The Disposal of Canada's Nuclear Fuel Waste: Postclosure Assessment of a Reference System. Report AECL-10717, COG-93-7.

[5] Atomic Energy of Canada Limited (AECL) 1996. The Disposal of Canada's Nuclear Fuel Waste: A Study of Post-closure Safety of In-room Emplacement of Used CANDU Fuel in Copper 
Containers in Permeable Plutonic Rock. Vol. 5: Radiological Assessment. Report AECL-114945, COG-95-552-5.

[6] Nagra. 2002. Project Opalinus Clay. Safety Report. Technical Report 02-05. Demonstration of Disposal Feasibility for Spent Fuel, Vitrified High-Level Waste and Long-Lived IntermediateLevel Waste (Entsorgungsnachweis). National Cooperative for the Disposal of Radioactive Waste. December.

[7] ANDRA. 2005. Dossier 2005 Argile - Tome. Évaluation de sûreté.

[8] SKB. 1999. SKB TR-99-23. SR 97 - Radionuclide Transport Calculations.

[9] SKB. 2006. SKB TR-06-09. Long-Term Safety for KBS-3 Repositories at Forsmark and Laxemar - a First Evaluation. Main Report of the SR-Can Project. Svensk Kärnbränslehantering AB. October.

[10] Garisto, N.C., S.L. Fernandes and F. Cooper 2008. No-Effect Concentrations for Screening Assessment of Radiological Impacts on Non-Human Biota. Prepared for NWMO. SENES Report 34622. In preparation.

[11] United States Department of Energy (U.S. DOE). 2000. DOE Standard. A Graded Approach for Evaluating Radiation Doses to Aquatic and Terrestrial Biota. Proj ENVR-0011. October.

[12] Environmental Risk from Ionising Contaminants: Assessment and Management (ERICA) 2007. ERICA Assessment Tool v1.0. August. 
